\title{
Predicting Factors of Interpersonal and Situational Influences for Performing Stretching Exercises Based on Pender's Model
}

\author{
Mohammad Hossein Delshad ${ }^{l}$, Sedigheh Sadat Tavafian ${ }^{l}$, Anoshirvan Kazemnejad ${ }^{2}$ \\ ${ }^{1}$ Health Education and Health Promotion Department, Faculty of Medical Sciences, \\ Tarbiat Modares University, Tehran, Iran. \\ ${ }^{2}$ Biostatistics Department, Faculty of Medical Sciences, Tarbiat Modares University, \\ Tehran, Iran. \\ Corresponding Author: Sedigheh Sadat Tavafian (Tavafian@modares.ac.ir)
}

\begin{abstract}
Background: Physical activity affects office employees in achieving a healthy lifestyle and preventing diseases such as Musculoskeletal Diseases (MSDS). Combining sports such as stretching exercises in healthy lifestyle programs is one of the most important decisions to prevent such disease.

Purpose: This study aimed to predict factors of interpersonal and situational influences for stretching exercise (SE) among office employees.

Methods: A cross-sectional study was conducted among 420 office employees recruited by multi-stage cluster sampling. Self-administered questionnaires of SE and interpersonal and situational influences based on Pender's Health Promotion Model, as well as socio-demographic data, were used in this study. The collected data were analyzed using Spearman correlation and logistic regression tests.

Results: Results showed that among 420 participants, the scores of interpersonal and situational influences, and SE were 4.6 $\pm 11.52,4.5 \pm 14.21$, and 2.48 \pm 17.64 , respectively. There was a significant relationship between interpersonal influence and SE ( $r=0.54$; $p<0.05)$, and undergoing treatment and SE $(r=0.77 ; p<0.05)$. There was no relationship between situational influence and SE $(r=0.107 ; p>0.05)$, and interpersonal influences were a strong predictor for SE behavior.

Conclusion: This study showed that the office employees who were more interpersonal influencers were more likely to do stretching exercise behavior. Therefore, interpersonal factors could be used as an educational principle in facilitating admission behavior of SE regarding Pender's Model.
\end{abstract}

Keywords: Healthy lifestyle; interpersonal influences; muscle stretching exercises; musculoskeletal diseases; situational influences

\section{BACKGROUND}

Physical activity is an activity that requires energy and is done and performed by the muscles and skeletal body (Lewis, Napolitano, Buman, Williams, \& Nigg, 2017). It is an important part of a healthy lifestyle and can reduce the risk of bone fractures. One form of physical activity is stretching exercises. Investigations showed that stretching behavior is a kind of physical exercise for flexed or stretched to achieve better muscle tone. Stretching behavior in Iran is relatively low, and there is no coherent program for 
training stretching, especially in offices (Pourhaji, Naserinia, Pourhaji, Pourhaji, \& Ranjbar, 2017).

Work-related musculoskeletal disorders (WMSDs) are a common cause of absenteeism in the workplace (Mansfield, Thacker, \& Smith, 2017; Tavafian, Jamshidi, Mohammad, 20174). A review by Mansfield et al. (2017) reported that the participation rate of people due to musculoskeletal disorders in physical activity programs is still low. This suggests that healthy people, as compared to people with skeletal musculoskeletal disorders in the workplace, show greater participation in physical activity (Delshad, Tavafian, \& Kazemnejad, 2017). Despite the existence of studies on the importance of exercising and decreasing sitting time in computer workers, especially stretching exercises; unfortunately, a small number of Iranian office employees are engaging with this issue (Delshad et al., 2017).

One of the models that are increasingly used in sporting activities is the Penders Health Promotion Model (Zare, Asadi, Vahedian-Shahroodi, \& Bahrami-Taghanaki, 2017). Two of the important factors on changing behavior in this model are the strategy of interpersonal influences and situational influences (Bennie et al., 2017). The interpersonal influential strategy is one factor of direct and indirect paths for any physical activity in both genders. Based on the health promotion model, an influential interpersonal factor is the knowledge of other behaviors, beliefs, or attitudes of others. These cognitions may or may not be compatible with reality (Khodaveisi, Omidi, Farokhi, \& Soltanian, 2017).

The situational influence is an approach that evaluates not only individual perceptions and cognition of any situation or context, but also how to behave as a facilitator or barrier to behavior. Situational influences on health promotion behaviors, such as exercises, include perceptions of existing options, desires or needs, and aesthetic features of an environment that behaves like exercises (Hsiao, Chien, Wu, \& Chiao, 2017). Individuals must be associated with and understand the behaviors, can order interpersonal interactions to be more likely to act in the direction of behavioral intention, and adapt and coordinate themselves with the cognitive symptoms associated with the behavior in question. On the other hand, the use of situational influences factor enables individuals to make more sporting behaviors by using environments or situations that feel calm, dependency, and in an environment or situation that is uneasy, alien, threatening and unhealthy, leading to successful behavior. Also, attractive and interesting environments, as a desirable background, help people transform their intent to behavior (Zhang et al., 2017).

In the health promotion model, both situational influences and interpersonal influences give direct and indirect effects on health behaviors. Interpersonal influences, in addition to the direct effect, are indirectly influenced by social pressures or persuasion to a commitment to a plan of action. The situational influences, in addition to the indirect effect, may be directly provided by a saturated environment from the guide that triggers of action, such as a slogan (exercise) that necessitates the characteristics of the behavior of exercise; in some way requires an obligation to exercise health (Yang, Luo, \& Chiang, 2017). 
Considering the important roles of interpersonal influences and situational influences on behavioral exercises as investigated in various studies (Hsiao et al., 2017; Mansfield et al., 2017; Shirvani, Sanaeinasab, Tavakoli, Saffari, \& Me'mar, 2017), it is necessary to predict the factors influencing stretching exercise behavior among office employees to improve and promote the SE behaviors.

\section{PURPOSE}

The present study aimed to predict the interpersonal and situational influences for stretching exercise (SE) among office employees.

\section{METHODS}

\section{Design and samples}

This study employed a cross-sectional research design. The samples were 430 office employees who were working in the three health networks of North, East and Shemiranat regions of Tehran and were affiliated to a university in Tehran, Iran. Ten health networks were randomly selected from May to September 2017. From each health network, office employees were randomly selected from eight comprehensive health service centers. The inclusion criteria were the individuals working in the university as an employee and working with the computer in his/her workplace. The excluding criteria were individuals sufferings from any disability or illness that prevented them from doing SE or being not allowed to do SE because of their physicians' recommendation.

\section{Instruments}

In this study, the demographic questionnaire, and self-administered questionnaires based on HPM (interpersonal influence, situational influences) regarding SE behaviors were used. The interpersonal influence was assessed using a 5-item questionnaire. This question evaluated through a 5-option scale: $1=$ never, $2=$ sometimes, $3=$ often, $4=$ very often, and 5=always. The rate for this statement was from never to always in a range of 1 to 5 . The total score ranges from 5 to 25 points; the higher score showed a better status. Situational influences were assessed using a nine-item questionnaire. The rate for each statement was evaluated through a 3-option scale from never to always in a range of 1 to 4 . The score criterion is from 9 to 36 points (Delshad, Tavafian, \& Kazemnejad, 2019). Questions that assessed the behavior of stretch marks included variables such as age, sex, marital status, occupation, level of education, work experience with computers, economic status, number of children and undergoing treatment. The selfreport was completed by the individuals at the time of 20 minutes.

The content validity of the questionnaires was confirmed by the experts' panel. These experts were 15 specialists (Sihawong, Janwantanakul, Sitthipornvorakul, \& Pensri, 2011), So, by studying books and similar articles and summing up the themes of interviews with health education and health promotion specialists and sports medicine experts, a questionnaire was set up and provided to professors, experts and experts in health education and health promotion of Sports Medicine and Occupational Health. The specialist's panel reviewed all of the items and supplied their consultants with a questionnaire and evaluated the questionnaire. The Content Validity Index (CVI) of the 
interpersonal influences and situational influences were 0.88 and 0.78 , respectively. It is also necessary to compute Content Validity Ratio (CVR) as a necessary criterion for terms "is useful, but not necessary, and does not require a statement" (Delshad et al., 2019). In this study, the content validity ratio of the interpersonal influencers was 0.82 , and for the situational influences of 0.79 . To determine the internal consistency of the questionnaire, a preliminary study was carried out on 30 employees with similar criteria to the research sample. The alpha range for interpersonal influences was 0.71 and for situational influences was 0.71 , indicating the internal consistency of the questionnaire. A questionnaire was used to measure stretching exercise behavior (Hutchinson et al., 2018).

\section{Data analysis}

The collected data were analyzed using SPSS software version 16 and Spearman correlation and logistic regression tests.

\section{Ethical consideration}

All ethical issues were considered in this study. The Research Ethics Committee of Tarbiat Modares University approved the study in May 2016 (ID 52/1115 IR.TMU.REC.1395.329).

\section{RESULTS}

\section{Socio-demographic characteristics of the respondents}

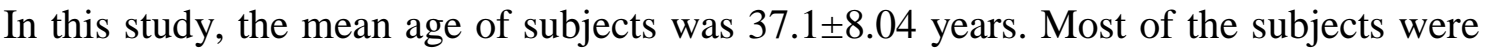
in the range of 34-34 years old (25.2\%), and the lowest percentage was in the target group of age $20-24(6.2 \%)$. Furthermore, $73.1 \%$ were women, and $26.9 \%$ were men. The mean score of interpersonal influencers was $11.55 \pm 4.6$, and the mean of situational influences was $14.21 \pm 4.5$. A total of 83 employees were treated for skeletal musculoskeletal problems (Table 1).

Table 1. Socio-demographic characteristics of the respondents

\begin{tabular}{lrc}
\hline Variables & $f$ & $\%$ \\
\hline Age $(37.1 \pm 8.03)$ & & \\
$21-24$ & 26 & 6.2 \\
$25-29$ & 45 & 10.7 \\
$30-34$ & 106 & 25.2 \\
$35-39$ & 78 & 18.6 \\
$40-44$ & 97 & 23.1 \\
45 and above & 68 & 16.2 \\
Number of children & & \\
$\quad$ No child & 176 & 41.9 \\
single child & 126 & 30 \\
Two & 89 & 21.2 \\
Three & 27 & 6.4 \\
Four & 2 & 0.5 \\
Work experience with computers & & \\
$\quad \leq 5$ years & 220 & 52.4 \\
5-10 years & 121 & 28.8 \\
\hline
\end{tabular}




\begin{tabular}{lrr}
\hline Variables & $f$ & $\%$ \\
\hline $11-15$ years & 55 & 13.1 \\
$16-20$ years & 23 & 5.5 \\
$\geq 20$ & 1 & 0.2 \\
\hline Suffering from WRMSD pain. & 154 & \\
$\quad$ Yes & 266 & 36.7 \\
$\quad$ No & & 63.3 \\
Economic situation (Rials) & 60 & 14.3 \\
$\quad$ Less than ten million & 80 & 19 \\
$\quad$ Ten million & 140 & 33.3 \\
10 to 20 million & 140 & 33.3 \\
$\quad$ More than 20 million & & \\
Undergoing treatment & 83 & 19.8 \\
$\quad$ Yes & 337 & 80.2 \\
$\quad$ No & &
\end{tabular}

Predictors of stretching exercise behavior based on health promotion model

The mean and standard deviation of the interpersonal influence score and the situational influence and the area to be acquired are presented in Table 2. As Table 2 shows, the situational negative influence was a negative predictor for engaging in stretching exercise [OR (\%95CI): 0.94(0.87-1.02), $p=0.158)$ ]. Furthermore, the results of this study showed interpersonal influences [OR (\%95CI): 1.42(1.21-1.41), $p=0.003)$ ] was a positive predictor for the stretching exercise behavior.

Table 2. Predictors of stretching exercise behavior based on health promotion model

\begin{tabular}{lllllll}
\hline Scale & Mean \pm SD & $\begin{array}{l}\text { Acquired } \\
\text { range }\end{array}$ & OR(\%95CI) & S.E & Beta & $p$ \\
\hline $\begin{array}{l}\text { Interpersonal } \\
\text { influence }\end{array}$ & $4.6 \pm 11.52$ & $0-25$ & $1.42(1.21-1.41)$ & 0.040 & 0.141 & 0.003 \\
$\begin{array}{l}\text { Situational } \\
\text { influences }\end{array}$ & $4.5 \pm 14.21$ & $0-36$ & $0.94(0.87-1.02)$ & 0.040 & -0.057 & 0.158 \\
$\begin{array}{l}\text { Stretching Exercise } \\
\begin{array}{l}\text { Undergoing } \\
\text { treatment }\end{array}\end{array}$ & $2.48 \pm 17.64$ & $35-0$ & $1.41(1.13-1.43)$ & 0.047 & 0.232 & 0.004 \\
Age & - & - & $4.15(1.54-11.19)$ & 0.506 & 1.42 & $p<0.05$ \\
\hline
\end{tabular}

The results of the analysis of odds ratios showed that there was a significant relationship between the underlying condition of the employees' work history due to musculoskeletal problems and stretching exercise behavior. Thus, the employees who were treated had a higher mean score for their stretching exercise behavior and the probability of gestures of stretching of the treated office employees' maybe 1.4 times more likely to be non-existent or not treated because of the perceived risk of nonexertion in the past. The variable of being treated as an accelerating factor in stretching is considered. 


\section{Relationship between predictors of stretching exercise behaviors with demographic characteristics}

The Spearman correlation test was used to examine the correlation between Situational Influences and Interpersonal Influence and Stretching Exercise behavior. The results are presented in Table 3.

Table 3. Relationship between predictors of stretching exercise behaviors and demographic characteristics

\begin{tabular}{llcccc}
\hline Scale & Age & $\begin{array}{l}\text { Undergoing } \\
\text { treatment }\end{array}$ & $\begin{array}{l}\text { Interpersonal } \\
\text { Influence }\end{array}$ & $\begin{array}{l}\text { Situational } \\
\text { Influences }\end{array}$ & $\begin{array}{l}\text { SE } \\
\text { behavior }\end{array}$ \\
\hline Age & - & & & & \\
Undergoing treatment & $r=0.115^{* *}$ & - & & - & \\
Interpersonal Influence & $r=0.046^{* *}$ & $r=-0.052$ & & & \\
Situational Influences & $r=0.003$ & $r=-0.031$ & $r=0.144^{* *}$ & - & \\
$\begin{array}{l}\text { Stretching Exercise } \\
\text { behavior }\end{array}$ & $r=-0.001^{* *}$ & $r=0.77^{* *}$ & $r=0.54^{* *}$ & $r=0.107$ & - \\
\hline
\end{tabular}

Spearman correlation coefficient $=\mathrm{p}<0.05 * *$

The Spearman's correlation coefficient showed that there was a significant relationship between interpersonal influencers and stretching behavior $(p<0.05$ and $r=0.54)$, but between Situational Influences and Stretching Exercise behavior $(p<0.05$ and $r=0.107)$, there was no meaningful relationship. Among the characteristics of respondents, there was a significant relationship between age and treatment in the office employees' $(r=0.15, p<0.05)$; the correlation of this relationship indicates a low level of communication.

\section{DISCUSSION}

This study aimed to predict the interpersonal and situational influences for stretching exercise (SE) among the office employees. The results of this study showed that interpersonal factors were the important predictors of stretching exercise behavior among office employees. This result supports previous studies reporting that factors of interpersonal influences were predictable. However, intrinsic influencers had no effect on them, and there was no correlation between these two interspecific and interpersonal criteria (Cho, Choi, Lee, \& Cho, 2015; McMahon et al., 2017).

Interpersonal influences are defined as cognitions concerning the behaviors, beliefs, or attitudes that decide people' predisposition to engage in health-promoting behaviors. The situational influences on health promotion behaviors include perceptions of existing options, desires or needs, and aesthetic features of an environment. In order to have situational interactions, individuals must be associated with the cognitive symptoms associated with the behavior in question. The behavior of office employees who do not engage in the usual exercise program could be prompted or inhibited through associated interpersonal influences, situational influences, and facilitators or barriers (Cho et al., 2015).

In the present study, due to the difference in age group, the severity of the relationship between interpersonal influencers and stretching exercises in the study of the status quo 
with correlation is better evaluated. Employees who have high interpersonal influences and those who are persuaded to a commitment to a plan of action stretching behaviors do so faster than those who do not interact with interpersonal influences or situational influences. In the older group, people are more interested in interpersonal relationships because of their loneliness, and this should not be neglected. However, in a qualitative study by Cho et al. (2015), the age of $62.6 \%$ (more than half of the healthy adult participants in urban areas) had no significant effect on health promotion of their physical activity. Furthermore, a review of the role of yoga in patients reported that there is a high degree of heterogeneity in the types of educational interventions in the study. The duration of treatment, exposure to the disease, various symptoms of the disease were as situational factors, disadvantages, benefits, and warnings in the person (Rao et al., 2017).

In the present study, planning with the help of interpersonal influences and situational influences strategies has had a strong impact on encouraging office employees' to elucidate stretching behavior. Due to the planning, the process of pre-occurrence and predetermination illuminates and helps fill the gap of intent and behavior (Lee, Small, \& Jacobsen, 2017). In this study, strategic planning using interpersonal influencers was one of the factors influencing the behavior of stretching exercises, and with the help of variable in the past due to musculoskeletal problems, of stretching behavior. Employees with high interpersonal influences do this behavior faster than those who do not interact with interpersonal influences. This study emphasizes the strategies for using interpersonal influences and special attention to the role of health planning. Therefore, it can be said that individuals are required to have appropriate planning strategies based on employees' beliefs to conduct stretching behavior, as what Kaushal and his colleagues have pointed out this long ago (Kaushal, Rhodes, Spence, \& Meldrum, 2017).

The result of the present study is in line with a study by Wu, Pender, and Yang (2002), reporting that among the major determinants of health behavior in the health promotion model are interpersonal influences and situational influences. The reason for the difference between predictors can be found in cultural differences in the importance of barriers to physical activity. It seems that beliefs about the benefits of sport and barriers among Iranian employees are more pronounced (Wu, Pender, \& Yang, 2002). As in the study of Cain, Meehan, Roche, Clarkin, and De Panfilis (2019), interpersonal influences affect everyday life and are an important dimension for interpersonal performances.

In numerous studies (Cho et al., 2015; Delshad, Hidarnia, \& Niknam, 2014; McMahon et al., 2017; Sihawong et al., 2011), the positive effects of stretching and yoga have been brought; however, in comparison with the present study, the history of treatment in the office employees' is considered as an accelerating factor in stretching. In the present study, the history of treatment for musculoskeletal problems is a good predictor of staffing for regular stretching exercises. However, individuals also experienced a reduction in their stressful behavior while enjoying yoga (Sullivan, Carberry, Evans, Hall, \& Nepocatych, 2017). Meanwhile, another study showed that yoga and boosting exercises on back pain did not have any significant statistical effect compared to adherence to evidence-based methods (Brämberg, Bergström, Jensen, Hagberg, \& 
Kwak, 2017). These results indicate that the behavior of employees in different populations is low regarding the easiest way to perform stretching exercises.

In the present study, there was no significant relationship between ages and stretching behavior. This result is inconsistent with a study by Palmer and Thompson (2017) and consistent with a study by McGuinness et al. (2017). Comprehensive health services centers are considered as an appropriate opportunity for promoting sports in health care providers and health team offices (Learmonth et al., 2017). In another study, the role of planning in health behaviors has been mentioned (Issel \& Wells, 2017). There is no evidence of stretching exercises and situational influences and beliefs about work constraints (Walker, Tullar, Diamond, Kohl, \& Amick, 2017).

Among the limitations of this study was the collection of information on the behavior of stretching exercises through self-reporting that individuals may report their behavior more than real. Also, considering the cross-sectional nature of this study, it is suggested to design and implement quasi-experimental studies to determine the exact effect of interpersonal influences and situational influences on stretching behavior. In addition, in this study, the sampling was based on cluster sampling, which might not be able to generalize this information to all Iranian office clerical groups. Despite the existing limitations, it seems valid in view of consistency with many other similar studies.

\section{CONCLUSION}

This study showed that the interpersonal factors were the most predicting factors for stretching exercise behavior among the office employees. Therefore, interpersonal factors to facilitate the acceptance of behavior can be considered as a training principle attention. Future educational studies can be used to predict the present study.

\section{ACKNOWLEDGMENT}

This article is the result of the thesis of the first doctoral dissertation at Tarbiat Modares University. The authors would like to thank the participants of this study.

\section{CONFLICT OF INTEREST}

The authors acclaimed that they have no rivaling interests.

\section{REFERENCES}

Bennie, J. A., Pedisic, Z., Suni, J. H., Tokola, K., Husu, P., \& Biddle, S. J. (2017). Selfreported health-enhancing physical activity recommendation adherence among 64,380 Finnish adults. Scandinavian Journal of Medicine \& Science in Sports, 27(2), 1842-1853. doi: 10.1111/sms.12863

Brämberg, E. B., Bergström, G., Jensen, I., Hagberg, J., \& Kwak, L. (2017). Effects of yoga, strength training and advice on back pain: A randomized controlled trial. BMC Musculoskeletal Disorders, 18(1), 132-136. doi:10.1186/s12891-017-1497-1.

Cain, N. M., Meehan, K. B., Roche, M. J., Clarkin, J. F., \& De Panfilis, C. (2019). Effortful control and interpersonal behavior in daily life. Journal of Personality Assessment, 101(3), 315-325. 
Cho, S.-H., Choi, M., Lee, J., \& Cho, H. (2015). Relationship between expectations regarding aging and physical activity among middle-aged adults in urban areas: Based on the Pender's health promotion model. Journal of Korean Academy of Nursing, 45(1),14-24.

Delshad, M. H, Hidarnia, A., \& Niknam, S. (2014). Psychometric measure continuous variables preventive behaviors of hepatitis B virus infection in health care workers. Journal of Mazandaran University of Medical Sciences, 24(109), 71-82.

Delshad, M. H., Tavafian, S. S., \& Kazemnejad, A. (2019). Designing and psychometric evaluation of stretching exercise influencing scale (SEIS). BMJ Open, 9(5), e026565. Doi:10.1136/bmjopen-2018-026565.

Delshad, M. H., Tavafian, S. S., \& Kazemnejad, A. (2017). The status of tension exercise behavior among Iranian office workers based on trans theoretical model. International Journal of Musculoskeletal Pain Prevention, 2(2), 251-256.

Hsiao, C.-Y., Chien, M.-J., Wu, H.-S., \& Chiao, C.-Y. (2017). Correlates of healthpromoting lifestyle behaviors among Vietnamese female immigrants in Taiwan. Women \& Health, 57(3), 342-357. doi:10.1080/03630242.2016.1160966.

Hutchinson, J., Headley, S., Matthews, T., Spicer, G., Dempsey, K., Wooley, S. (2018). Changes in sitting time and sitting fragmentation after a workplace sedentary behaviour intervention. International Journal of Environmental Research and Public Health, 15(6), 1148-53. doi: 10.3390/ijerph15061148.

Issel, L. M., \& Wells, R. (2017). Health program planning and evaluation. Burlington, USA: Jones \& Bartlett Learning.

Kaushal, N., Rhodes, R. E., Spence, J. C., \& Meldrum, J. T. (2017). Increasing physical activity through principles of habit formation in new gym members: A randomized controlled trial. Annals of Behavioral Medicine, 51(4), 578-586. doi:10.1007/s12160-017-9881-5.

Khodaveisi, M., Omidi, A., Farokhi, S., \& Soltanian, A. R. (2017).The effect of Pender's health promotion model in improving the nutritional behavior of overweight and obese women. BMJ Open, 7(1).131-139. doi: 10.1136/bmjopen2016-015415.131.

Learmonth, Y. C., Adamson, B. C., Balto, J. M., Chiu, C.-Y., Molina-Guzman, I. M., Finlayson, M. (2017). Investigating the needs and wants of healthcare providers for promoting exercise in persons with multiple sclerosis: A qualitative study. Disability and Rehabilitation, 40(18), 2172-2180. doi: 10.1080/09638288.2017.1327989.

Lee, M. S., Small, B. J., \& Jacobsen, P. B. (2017). Rethinking barriers: A novel conceptualization of exercise barriers in cancer survivors. Psychology, Health \& Medicine, 22(10), 1248-1255. doi: 10.1080/13548506.2017.1325503.

Lewis, B. A., Napolitano, M. A., Buman, M. P., Williams, D. M., \& Nigg, C. R. (2017). Future directions in physical activity intervention research: Expanding our focus to sedentary behaviors, technology, and dissemination. Journal of Behavioral Medicine, 40(1), 112-126.

Mansfield, M., Thacker, M., \& Smith, T. (2018). Physical activity participation and the association with work-related upper quadrant disorders (WRUQDs): A systematic review. Musculoskeletal Care, 16(1), 178-187. doi: 10.1002/msc.1204. 
McGuinness, M. B., Le, J., Mitchell, P., Gopinath, B., Cerin, E., Saksens, N. (2017). Physical activity and age-related macular degeneration: A systematic literature review and meta-analysis. American Journal of Ophthalmology, 180, 29-38. doi: 10.1016/j.ajo.2017.05.016.

McMahon, S. K., Lewis, B., Oakes, J. M., Wyman, J. F., Guan, W., \& Rothman, A. J. (2017). Assessing the effects of interpersonal and intrapersonal behavior change strategies on physical activity in older adults: A factorial experiment. Annals of Behavioral Medicine, 51(3), 376-390. doi: 10.1007/s12160-016-9863-z.

Palmer, T. B., \& Thompson, B. J. (2017). Influence of age on passive stiffness and size, quality, and strength characteristics. Muscle \& Nerve, 55(3), 305-315. doi: $10.1002 /$ mus.25231.

Pourhaji, F., Naserinia, S. J., Pourhaji, F., Pourhaji, R., \& Ranjbar, H. (2017). Educational ergonomic intervention and work-related musculoskeletal disorders among office workers in Tehran, Iran. IJMPP, 1(2), 61-67.

Rao, R. M., Amritanshu, R., Vinutha, H., Vaishnaruby, S., Deepashree, S., Megha, M. (2017). Role of yoga in cancer patients: Expectations, benefits, and risks: A review. Indian Journal of Palliative Care, 23(3), 225-230. doi: 10.4103\%2FIJPC.IJPC_107_17.

Shirvani, H., Sanaeinasab, H., Tavakoli, R., Saffari, M., \& Me'mar, S. (2017). The effect of a social cognitive theory-based educational intervention on the physical activity of female adolescents. Iranian Journal of Health Education and Health Promotion, 4(4), 309-318.

Sihawong, R., Janwantanakul, P., Sitthipornvorakul, E., \& Pensri, P. (2011). Exercise therapy for office workers with nonspecific neck pain: A systematic review. Journal of Manipulative and Physiological Therapeutics, 34(1), 62-71. doi: 10.1016/j.jmpt.2010.11.005.

Sullivan, M., Carberry, A., Evans, E. S., Hall, E. E., \& Nepocatych, S. (2017). The effects of power and stretch yoga on affect and salivary cortisol in women. Journal of Health Psychology, 1(1), 1-10. doi: 10.1177\%2F1359105317694487.

Tavafian, S. S., Jamshidi, A. R., \& Mohammad, K. (2017). Treatment of low back pain: Randomized clinical trial comparing a multidisciplinary group-based rehabilitation program with oral drug treatment up to 12 months. International Journal of Rheumatic Diseases, 17(2), 159-16.

Walker, T. J., Tullar, J. M., Diamond, P. M., Kohl, H. W. I., \& Amick, B. C. I. (2017). Association of self-reported aerobic physical activity, muscle-strengthening physical activity, and stretching behavior with presenteeism. Journal of Occupational and Environmental Medicine, 59(5), 474-479. doi:10.1097/jom.0000000000000978

Wu, T. Y., Pender, N., \& Yang, K. P. (2002). Promoting physical activity among Taiwanese and American adolescents. The journal of nursing research: JNR, 10(1), 57-64.

Yang, S.-C., Luo, Y.-F., \& Chiang, C.-H. (2017). The associations among individual factors, eHealth literacy, and health-promoting lifestyles among college students. Journal of Medical Internet Research, 19(1), 15-21. https://doi.org/10.2196/jmir.5964. 
Zare, M., Asadi, Z., Vahedian-Shahroodi, M., \& Bahrami-Taghanaki, H. (2017). Investigating the relationship between components of Pender's health promotion model and self-care behaviors among patients with smear-positive pulmonary tuberculosis. Evidence-Based Care, 6(4), 7-17. doi: 10.22038/ebcj.2016.7983.

Zhang, P., Hu, Y.-d., Xing, F.-M., Li, C.-Z., Lan, W.-F., \& Zhang, X.-L. (2017). Effects of a nurse-led transitional care program on clinical outcomes, health-related knowledge, physical and mental health status among Chinese patients with coronary artery disease: A randomized controlled trial. International Journal of Nursing Studies, 74, 34-43. doi: 10.1016/j.ijnurstu.2017.04.004. 